\title{
ОСНОВНЫЕ ПРИНЦИПЫ ВВОДНОГО АЛФАВИТНОГО КУРСА, РЕАЛИЗУЕМОГО НА ОТДЕЛЕНИИ РУССКОЙ ФИЛОЛОГИИ
}

\author{
DOROTA DZIEWANOWSKA \\ Uniwersytet Pedagogiczny im. KEN w Krakowie \\ Instytut Neofilologii, Katedra Dydaktyki Języka Rosyjskiego \\ ul. Studencka 5, 31-116 Kraków, Polska \\ e-mail: ddziewanowska@o2.pl \\ (nadesłano 30.07.2017; zaakceptowano 8.08.2017)
}

\section{Abstract \\ Main principles of the introductory alphabetic course in the first year of Russian philology studies}

The article presents the principles of forming the writing technique among university students who start learning Russian from scratch. The author believes that teaching writing techniques in beginners' groups should follow the principle of complexity. According to the author, the parallel forming of graphic and calligraphic habits should be connected with forming phonetic habits, as well as learning spelling and lexical-grammatical material. In the article, the teaching techniques which may be used during the introductory alphabetic course are presented. Moreover, the difficulties of Polish students in the process of learning Russian calligraphic, phonetic and spelling norms are discussed.

\section{Key words}

Russian alphabet, writing technique, calligraphy, spelling, articulation, intonation. 


\section{Резюме}

В настоящей статье описаны принципы формирования техники письма у студентов-русистов, которые начинают изучать русский язык с азбуки. Автор статьи считает, что в нулевых студенческих группах обучение технике письма должно соответствовать принципу комплексности. По мнению автора, параллельное формирование графических и каллиграфических навыков должно сочетаться с формированием фонетических навыков, а также с изучением орфографического и лексико-грамматического материала. В статье указывается на приемы работы, которые могут быть применены в ходе вводного алфавитного курса, и на трудности польских студентов, связанные с усвоением норм русской каллиграфии, фонетики и орфографии.

\section{Ключевые слова}

Русский алфавит, каллиграфия, орфография, артикуляция, интонация.

Письменная речь как вид речевой деятельности включает в себя письмо и собственно письменную речь. Обучение письму - это «обучение графической и орфографической системам языка для записи отдельных слов, словосочетаний, предложений, формирование навыков фиксировать устную речь с помощью графических знаков» ${ }^{1}$. Обучение собственно письменной речи связано с выработкой умения «сочетать слова в письменной форме для выражения своих мыслей в соответствии с потребностями общения» ${ }^{2}$. Иначе говоря, письмо связано с развитием техники письма, а обучение письменной речи непосредственно связано с развитием коммуникативных умений.

В настоящее время в польских школах наблюдается недооценивание роли формирования навыков в области письма в процессе обучения как родному языку, так и иностранным языкам. По моему мнению, причину этого следует усматривать в том, что заложенная коммуникативным методом направленность на практическое овладение иностранным языком привела к усилению тенденции обучать устной речи. Свой отпечаток оставил также технологический бум, наблюдаемый в конце XX века и в начале XXI века. Применение в дидактическом процессе компьютерных технологий выразилось в пренебрежении к формированию каллиграфических навыков. Это наблюдение относится также к обучению русскому языку как иностранному на филологическом факультете. В последнее время во многих вузах, в том числе и в Краковском педагогическом университете, на отделение русской филологии стали поступать абитуриенты с нулевым знанием русского языка. В новой дидактической ситуации обучение технике письма является начальной стадией обучения языку. Иначе говоря, до

1 Э.Ю. Сосенко. Обучение письменной речи. [В:] Методика. Заочный курс повышения квалификаичи филологов-русистов. Ред. А.А. Леонтьев. Москва: Русский язык, 1988, с. 142.

2 Там же, с. 142. 
формирования умений в области репродуктивной и продуктивной письменной речи студентам необходимо овладеть техникой письма, т.е. познакомиться с русским алфавитом, овладеть правилами русской графики и орфографии.

В настоящей статье сделана попытка наметить новые пути формирования графических навыков у студентов-русистов, начинающих изучать русский язык с азбуки.

Под термином графика С.И. Лебединским и Л.Ф. Гербик понимается

совокупность начертательных средств того или иного письма, включающая графемы, знаки препинания, знак ударения и др.; система отношений между графемами и фонемами в фонематическом письме. Соответственно, графические навыки - это навыки владения этими средствами, навыки их использования при письме и узнавания при чтении. Другое их название, встречающееся в методической литературе, - навыки техники чтения и письма ${ }^{3}$.

С точки зрения М.А. Рычковой,

графика - это совокупность всех средств письменности данного языка: буквы, отношения между звуками речи и обозначающими их буквами, знаки препинания и выделения, абзацы, условные подчеркивания и шрифтовые выделения ${ }^{4}$.

М.А. Рычкова считает, что усвоение графики, т. е. умение правильно соотносить звук и букву, составляет основу развития орфографических умений и навыков.

В лингводидактической литературе разграничиваются два понятия: «графика» и «каллиграфия». По мнению Т.М. Балыхиной, «графика (от греч. grapho «пишу») подразумевает совокупность основных начертательных средств (буквы, буквосочетания и др.) для изображения звуков и звукосочетаний языка на письме» ${ }^{5}$ В свою очередь «каллиграфия (от греч. kalligraphia «красивый почерк») представляет собой умение писать четко, разборчиво и красиво, даже искусно» ${ }^{6}$.

Более образное определение понятия «каллиграфия» дает М.А. Рычкова, которая пишет: «Каллиграфия - это наиболее сокровенная, личная, спонтанная форма выражения. Подобно отпечатку пальцев или голосу, она уникальна для каждого человека (...) Древние восточные мудрецы говорили: Каллиграфия это не только искусство идеального написания слов, но и искусство идеального духа!» ${ }^{7}$.

3 С. И. Лебединский, Л. Ф. Гербик. Методика преподавания русского языка как иностранного. Учебное пособие. Минск: РИВШ БГУ, 2011, с. 278. [Online:] <www.bsu.by/Cache/pdf/365803.pdf> (20.01.2016).

4 М.А. Рычкова. Каллиграбия для взрослых. Учебное пособие. Улан-Удэ: ФГОУ ВПО Бурятская государственная сельскохозяйственная академия им. В.Р. Филиппова, 2009, с. 66.

5 Т.М. Балыхина. Методика преподавания русского языка как неродного (нового). Учебное пособие для преподавателей и студентов. Москва: Издательство Российского университета дружбы народов, 2007, с. 150.

6 Т.М. Балыхина. Методика преподавания русского языка как неродного..., с. 150.

7 М.А. Рычкова. Каллиграбия для взросльх ..., с. 5. 
В российской методике формирования графических и каллиграфических умений соблюдаются строгие правила: 1) буквы в словах надо писать с одинаковым наклоном в 65 градусов, 2) необходимо писать буквы в словах на одинаковом расстоянии друг от друга, 3) буквы должны быть одинаковой высоты, 4) слог пишется безотрывно, 5) писать надо быстро и красиво ${ }^{8}$.

Вопрос о необходимости соблюдения или несоблюдения при обучении иноязычных учащихся графике и каллиграфии строгих требований, принятых в российских школах, вызывает много дискуссий. Большинство российских лингводидактов считает, что нужно требовать от иностранных учащихся написания букв с наклоном вправо. По моему мнению, нельзя упускать из виду тот факт, что в Польше и во многих других европейских странах распространено прямое письмо, поэтому письмо с наклоном вправо вызывает трудности у учащихся. Проведенное мною в 1984-1986 гг. экспериментальное обучение русскому языку с применением репродуктивно-креативного метода подтверждает тезис о том, что при обучении русской графике и каллиграфии не надо заставлять польских учащихся соблюдать все требования, относящиеся к письму, которые ставятся школьникам в России. В условиях работы с польскими учащимися достаточно, чтобы они научились правильно соединять буквы, например буквы $\pi, \mathcal{M}, я$, с предшествующими буквами и буквы $a, o, y$ с последующими буквами. Основная цель обучения русской графике и каллиграфии польских обучаемых - сформировать правильное, разборчивое и довольно скорое письмо9. Эти требования должны соблюдаться также при обучении письму студентов-русистов, начинающих изучать русский язык с азбуки.

Важным с лингводидактической точки зрения является вопрос, касающийся последовательности введения букв. Э.Ю. Сосенко считает, что русские буквы надо вводить с учетом степени возрастания трудности их написания. К буквам нулевого ранга сложности относятся: $2, o, c, b$. К буквам первого ранга сложности, т.е. объединяющим два элемента, относятся: $\partial, y, a$. При обучении русской графике допускается также использование комбинированного метода, т.е. буквы группируются в серии по общности графических элементов, например: $o, a$, $ю, \partial, \sigma, \oint$ или $u, \breve{u}, \mathcal{u}, u_{s}, w_{s}, y^{10}$. Однако, следует отметить, что в польской лингводидактике последовательность изучения букв определяется не характером русской графики, а требованиями алфавитного курса и реализуемых в его ходе лексических тем, что отвечает требованиям коммуникативного метода и необходимости формирования коммуникативной компетенции.

Графическое и каллиграфическое оформление письменного текста состоит из ряда взаимосвязанных операций: «звукового представления, звукового и зрительного восприятия, ассоциирования звуков с соответствующими графемами,

8 См. М.А. Рычкова. Каллиграфия для взросльх..., с. 40.

9 Zob. D. Dziewanowska. Kształtowanie sprawności mownych w procesie nauczania języka rosyjskiego metoda reproduktywno-kreatywna w klasie V i VI szkoły podstawowej. Seria Prace Monograficzne, nr 175, Kraków: Wydawnictwo Naukowe WSP, 1993, c. 13-14.

10 См. Э.Ю. Сосенко. Обучение письменной речи..., с. 144. 
рукомоторной деятельностью, сочетающейся с внутренней речью» ${ }^{11}$. Поэтому в нулевых студенческих группах обучение технике письма должно полностью соответствовать принципу комплексности в обучении видам речевой деятельности. В Краковском педагогическом университете при изучении азбуки на занятиях практикума русского языка особое внимание уделяется не только написанию букв, но и звукобуквенным соответствиям. Параллельное формирование графических, каллиграфических и произносительных навыков осуществляется в тесной связи с обучением слушанию, говорению и чтению при одновременном изучении орфографического и лексико-грамматического материала.

При обучении русской графике польских студентов следует иметь в виду то, что приступая к изучению русской графики, они уже обладают прочно сформированными навыками письма на родном языке, которые нередко затрудняют изучение русской графики. Преимущественно эти трудности связаны с написанием букв, а также со звукобуквенными соответствиями. В ходе алфавитного курса наши студенты узнают в русском алфавите:

a) уже знакомые им буквы, например: $a, \kappa, o$;

б) буквы, совпадающие с польскими буквами, но обозначающие другие звуки, например: $8, p, c, y$;

в) совершенно новые графические символы, например: $2, \mathcal{H}, \mathcal{u}, \mathfrak{w}, \mathfrak{w}, \ni$;

В процессе обучения в центре внимания преподавателя должны находиться, главным образом, две последние группы букв, усвоение которых нередко доставляет студентам большую трудность.

Эти трудности должны преодолеваться в ходе введения букв и тренировки в их написании. Целесообразно вводить русский звук в слове и сразу же соответствующую этому звуку букву. Преподаватель произносит слово, содержащее букву, и пишет на доске эту букву, а затем демонстрирует, как пишутся ее элементы, обращая при этом внимание обучаемых особенно на те элементы, которые отличаются от графики родного языка. Преподаватель должен также показывать направления движения руки при написании данной буквы (букв) на доске.

На начальной стадии обучения русским буквам каждую букву надо вводить изолированно. Затем буква пишется в сочетаниях с другими буквами, в составе слога и слова. При этом необходимо обращать внимание на соединение букв с предшествующими буквами и с последующими буквами, например: $a \pi$, ол, cм,

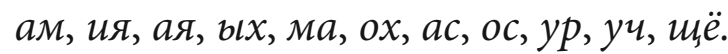

Учитывая тот факт, что на этом этапе обучение письму сочетается с обучением чтению, каждому вводимому звуку должны соответствовать четыре буквы: две рукописные (прописная и строчная) и две печатные (прописная и строчная). Такая дидактическая процедура способствует формированию звукобуквенных связей.

Обучение графике и каллиграфии должно строиться на когнитивной основе. Сознательное овладение закономерностями русской графики и каллиграфии является наиболее результативным приемом, ускоряющим процесс обучения

11 Т.М. Балыхина. Методика преподавания русского языка как неродного..., с. 150. 
и усвоения. Однако надо помнить, чтобы комментарии преподавателя передавались в сжатой форме. Приведем несколько примеров:

Если вы пишете букву в слоге, сочетании и в слове, подумайте, откуда начинается следующая буква: сверху, снизу или с середины строки.

Если следующая буква начинается сверху, то соединительную линию надо продолжать к верхней линейке строки.

Если следующая буква начинается снизу, то соединительную линию надо начертать вправо внизу, немного выше нижней линейки строки.

Если следующе букву можно написать не отрывая руки, то линию надо продолжить к середине строки и сделать плавное соединение.

По нашему мнению, на этапе предъявления букв и тренировки в их написании хорошим приемом работы является ведение руки учащегося (рука учащегося в руке преподавателя). Такое упражнение может выполняться на доске или в тетради учащегося. Можно также применить технику воображаемого письма, т.е. письма в воздухе, когда учащиеся по написанному на доске образцу поднятой рукой отображают в воздухе, как пишутся элементы буквы (букв). Не менее пригодным приемом является обведение букв по шаблону с предварительным зрительным и двигательным анализом элементов буквы. По моим наблюдениям, для фронтальной работы с группой пригоден ритмический прием, т.е. письмо в одинаковом ритме. При написании буквы «И»: 1 -движение руки вниз, 2 - делаем крючок, 3 - движение руки вверх, 4 - движение руки вниз, 5 - делаем крючок до середины строки. На примере буквы «И» можно легко объяснить принцип безотрывного письма и показать момент соединения букв. При соединении буквы «и» и буквы «м» выполняются движения 1-5, затем 6 - делаем точку, 7 - снова движение руки вниз, 8 - делаем крючок, 9 - движение руки вверх и т.д. Несомненным преимуществом этого упражнения является то, что оно способствует развитию плавности движении руки и уверенность руки, а также устанавливает нужную скорость письма.

При обучении русской графике следует использовать две группы упражнений: упражнения в начертании букв (каллиграфические упражнения) и упражнения на звукобуквенные соотношения.

В первую очередь мы приведем примеры каллиграфических упражнений, которые могут заключаться в написании элементов букв по образцу, переписывании букв, переписывании буквенных сочетаний, переписывании слов, переписывании предложений, переписывании микротекстов (по образцу), в группировке данных в разбивку строчных и прописных букв, в написании печатных букв прописью, переписывании печатных образцов прописью, написании алфавита, написании слов или предложений по памяти ${ }^{12}$.

Приведенные выше примеры упражнений предназначены для учащихся школьного возраста, но представляется, что они успешно могут применяться в нулевых студенческих группах. По нашему мнению, студентам полезно предложить задание, заключающееся в анализе своих графических ошибок и написании правильных вариантов. В студенческих группах не менее пригодным

12 См. Э.Ю. Сосенко. Обучение письменной речи..., с. 144. 
заданием является выписывание из текста слов, относящихся к данной тематической теме.

Обучение взрослых обучаемых технике письма иногда является кропотливой работой и требует терпения как со стороны преподавателя, так и студентов. Этот процесс усложняется тем более, что у студентов имеются прочно сформированные графические и каллиграфические навыки в области родного языка.

К числу наиболее частых графических ошибок можно отнести неправильное начертание букв и несоблюдение норм соединения букв. Довольно часто встречаются ошибки, связанные с несоблюдением норм написания деталей букв. Например, несмотря на то, что русские буквы отличаются от латинских начертанием, студенты пишут некоторые из них с использованием латинского алфавита. Отметим, что многие буквы польского алфавита пишутся выше строки $(k, t, h$, l). Под влиянием графических навыков алфавита родного языка наши студенты пытаются писать некоторые русские буквы выше строки, преимущественно букву $\kappa$ и л. Однако известно, что русский алфавит характеризуется небольшим количеством букв, которые пишутся выше строки, чаще всего русские буквы

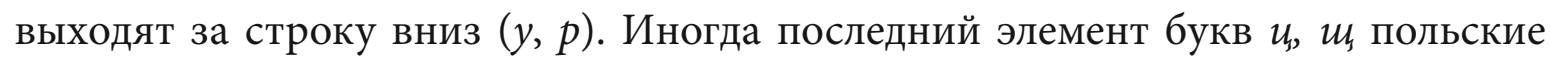
студенты пишут на такой же высоте как петли у польских букв $g, j, y$. Причину возникновения такого рода ошибок можно усматривать в интерференции каллиграфических навыков родного языка.

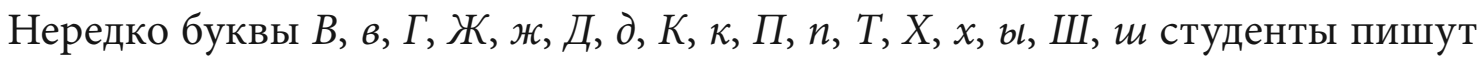
согласно печатным образцам. По-моему, эти ошибки являются следствием чрезмерного использования компьютера и сотовых телефонов.

У наших студентов наблюдаются и другие погрешности, которые связаны с несоблюдением однородного наклона букв. Как упоминалось выше, в Польше распространено прямое написание букв или с небольшим наклоном, поэтому мы не настаиваем на том, чтобы наши студенты писали буквы русского алфавита с наклоном в 65 градусов. Однако крупной каллиграфической ошибкой можно считать написание в одном слове букв с наклоном влево, вправо или без наклона. Многие каллиграфические ошибки связаны с нарушением пропорции букв, т.е. с неодинаковой высотой букв или их частей, или же с неодинаковой шириной букв или их элементов.

Отметим, что последние погрешности, совершаемые студентами, являются последствием непрочно сформированных каллиграфических навыков в процессе школьного обучения польскому языку. Они свидетельствуют также о том, с какими трудностями встречаются преподаватели, ведущие занятия практикума русского языка на первом курсе в студенческих группах нулевого уровня.

Нередко буквы, внешне сходные в русском и польском алфавите, но обозначающие различные звуки, студенты пишут соответственно буквам, имеющимся в польской графике. Например, на начальных стадиях обучения на месте русской буквы «п» студенты пишут букву p: nana - papa, на месте русской буквы $\mathcal{M}$ студенты пишут букву $m:$ мама - mama, на месте русской буквы 2 студенты

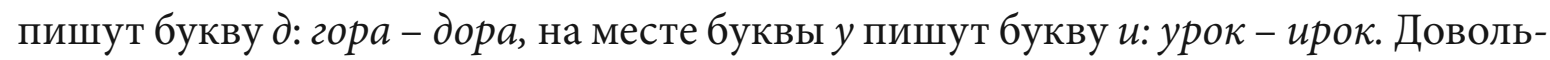
но часто студенты обозначают на письме звук [б] буквой в, например: бабушка - вавушка, а звук $[u]$ обозначают на письме с помощью буквы $c$, например: изена 
- сена. Преодолеть эти трудности можно довольно быстро при условии, что обучение буквам русского алфавита строится с учетом особенностей графики родного языка обучаемых. При этом преподаватель должен обращать внимание как на расхождения в графике родного и изучаемого языков, так и на их сходства.

Согласно нашим наблюдениям, большинство графических ошибок является следствием плохо усвоенной русской фонетики. Поэтому, как упоминалось выше, очень важно, чтобы с первых занятий параллельно формировались каллиграфические и произносительные навыки студентов. Отметим, что обучение польских студентов нормам русской фонетики уже имеет свои традиции в Краковском педагогическом университете, в котором с 1963 года применяется репродуктивно-креативный метод, автором которого является профессор Януш Генцель. Основные теоретические принципы обучения нормам русской фонетики изложены им в монографии Обучение русскому языку репродуктивно-креативным методом ${ }^{13}$ и в последующих работах. Этот метод нашел также применение в школьном обучении ${ }^{14}$. Следует сказать, что обучение русскому произношению как студентов-филологов, так и школьников согласно принципам репродуктивно-креативного метода давало положительные результаты. Однако в новой сложившейся в нашей стране дидактической ситуации, когда студенты-русисты начинают изучать русский язык с азбуки, приходится переосмыслить этапы и принципы обучения русскому произношению. Подробному обсуждению этих вопросов я посвятила отдельную статью: Новые требования к обучению русскому образцовому произношению польских студентов-русистов, изучающих русский язык с нулевого уровня ${ }^{15}$. Поэтому в настоящей статье предлагаю сосредоточиться преимущественно на обучении русскому произношению как неотъемлемому компоненту обучения письму.

При обучении букв и звуков в сознании студентов должна быть установлена связь между звуком и возможными вариантами его графического изображения. Согласно сказанному выше, отработку артикуляционного явления следует начинать с предъявления произношения звука в слове или же в нескольких словах (лишь особо трудные для польских студентов звуки полезно отрабатывать в изолированном положении $)^{16}$. Непосредственно после объяснения правил артикуляции звука и имитации его речевого образца вслед за преподавателем необходимо перейти к обсуждению его графического изображения и тренировке в его написании. Важно, чтобы всякие комментарии, касающиеся произношения и написания букв, сводились к минимуму. Буквы вводятся в изолированной форме, затем в сочетаниях с другими буквами, в составе слога, но непременно нужно переходить к упражнениям на несложных словах и предложениях. Кроме

13 Zob. J. Henzel. Nauczanie języka rosyjskiego metoda reproduktywno-kreatywną. Kraków: Wydawnictwo Naukowe WSP, 1978.

14 Zob. D. Dziewanowska. Kształtowanie sprawności mownych..., 1993.

15 См. Д. Дзевановская. Новые требования к обучению русскому образцовому произнотению польских студентов-русистов, изучающих русский язык с нулевого уровня. «Studia Rossica Posnaniensia» 2013, № 38. Ред. Е. Калишан, с. 53-63.

16 См. там же, с. 57. 
фонетических упражнений, заключающихся в чтении вслух вслед за преподавателем, а также в индивидуальном чтении студентами ряда слов или же несложных предложений, выполняются упражнения по транскрибированию слов или словосочетаний. Активное овладение фонетической транскрипцией дает студентам возможность лучше осознать особо трудные для них артикуляционные явления, а также способствует прочному закреплению фонетических правил. На этом этапе особого внимания заслуживают упражнения, направленные на формирование звукобуквенных соответствий. К самым результативным можно отнести следующие: чтение вслух слов, предложений; списывание букв, слогов, слов и предложений с доски, из учебника; заполнение пропусков в слове; заполнение пропусков в предложении; диктанты (буквенные, слоговые, словарные и фразовые); слушание и одновременное чтение слов, предложений и текстов ${ }^{17}$.

К не менее пригодным можно отнести упражнения, заключающиеся в написании букв со слуха, в усложненном списывании с подчеркиванием определенных букв, в усложненном списывании с подчеркиванием слов, в которых количество звуков не совпадает с количеством букв, в усложненном списывании с подчеркиванием буквы, которая не имеет звукового значения ${ }^{18}$.

На этом этапе обучения русскому языку студенты учатся читать слоги, слова, словосочетания, предложения и краткие тексты, а также задавать вопросы, отвечать на них, составлять краткие тексты по изученным темам, поэтому необходимо знакомить их с основными интонационными конструкциями (ИК-1, ИК2, ИК-2а, ИК-3, ИК-4 и ИК-5), а также с правилами синтагматического членения высказывания. Подобно обучению артикуляции, обучение интонации должно осуществляться на когнитивной основе. Процесс формирования интонационных навыков должен состоять из нескольких фаз: 1) предъявление правила; 2) звуковое предъявление мелодической линии данной интонационной конструкции (ИК) и демонстрация схемы, иллюстрирующей графическую запись мелодической линии ИК; 3) имитация по образцу предложения вслед за преподавателем; 4) выполнение тренировочных интонационных упражнений; 5) выполнение закрепительных упражнений ${ }^{19}$.

При постановке интонации необходимо ознакомить студентов с частями данной интонационной конструкции и изменением тона в пределах частей ИК. Овладение интонаций обеспечивается применением следующих процедур:

- произнесение всех частей интонационной конструкции с разной громкостью: предцентровую часть нормальным голосом, центр - громко, постцентровую часть - очень тихо;

17 См. Т.И. Капитонова, Л.В. Московкин. Методика обучения русскому языку как иностранному на этапе подготовки. Санкт-Петербург: Златоуст, 2006, с. 123.

18 См. Э.Ю. Сосенко. Обучение письменной речи..., с. 144.

19 См. Д. Дзевановская. Новые требования к обучению русскому образиовому произномению польских студентов-русистов.., s. 59. 
- использование движений рук - преподаватель, произнося предложение, показывает рукой изменение тона. Студенты повторяют за ним это движение и произносят предложение, сначала про себя, а затем вслух ${ }^{20}$.

Закреплению интонационных навыков способствует выполнение:

1) упражнений с постепенно увеличивающейся постцентровой частью, например: Он. Он учится. Он учится в университете.; Где? Где ты был? Где ты был летом?; Ваша ручка? Ваша ручка лежит на столе?

2) упражнений на изменение интонационного центра в предложении, например: Как ваша фамилия? Как ваша фамилия?; Твою подругу зовут Анна? - Да, Анна. Твою подругу зовут Анна? - Нет, сестру. Твою подругу зовут Анна? Да, мою.

3) упражнений на противопоставление, например, ИК-1 и ИК-2а (Это моя ручка. Это моя ручка!); ИК-2, ИК-2а (Кто это сказал? Кто это сказал!); ИК-1 и ИК-3 (Антон изучает литературу. Антон изучает литературу?) ${ }^{21}$. Упражнения на изменение интонационного центра помогают студентам лучше осмыслить интенцию данного высказывания и тем самым готовят их к реальной языковой коммуникации. В свою очередь, упражнения, построенные по принципу противопоставления, с одной стороны, противодействуют спутыванию интонационных конструкций, с другой стороны - готовят студентов к выполнению упражнений, направленных на употребление интонационных конструкций в многосинтагменных предложениях.

Следует подчеркнуть, что в ходе алфавитного курса, в течение нескольких (трёх-четырех) первых недель, невозможно ознакомить студентов со всеми фонетическими особенностями русского языка. Совершенствование фонетических навыков студентов и дальнейшее обучение закономерностям артикуляции и интонации должно являться неотъемлемым компонентом занятий по практикуму русского языка на всех последующих этапах обучения. Мой опыт работы со студентами старшекурсниками показал, что хорошие результаты дает опережение коммуникативных задач выполнением тренировочных фонетических упражнений. Предварительная отработка фонетических явлений, связанных с актуально изучаемым языковым материалом, требует выделения отдельного компонента занятий, занимающего 5-10 минут. Поскольку тренировочные упражнения предшествуют упражнениям в говорении, отбор фонетических явлений полностью подчиняется темам, вытекающим из коммуникативных задач, осуществляемых на данном занятии, и полностью зависит от преподавателя. Исходя из положения, что обучение нормам русской фонетики должно строиться на когнитивной основе, при выполнении тренировочных упражнений необходимо обращаться к соответствующим фонетическим правилам. Кроме того, при презентации произношения мы рекомендуем графически иллюстрировать артикуляционные явления, пользуясь знаками фонетической транскрипции. Тренировочные упражнения по существу опираются на слова или предложения, выступающие в изолированной позиции. Именно поэтому очень

20 См. там же, с. 59.

21 См. там же, c. 60-61. 
важно, чтобы отработанные слова и фразы непременно включались в состав осмысленного коммуникативного высказывания. В свою очередь, при выполнении интонационных упражнений, на наш взгляд, положительные результаты дает использование схем, иллюстрирующих мелодическую линию данной ИК.

Отметим, что выработка правильных артикуляционных навыков способствует повышению корректности речи в плане ударения и служит базой для дальнейшего обучения русскому словесному ударению с учетом лингвистической информации ${ }^{22}$. Степень владения правильной артикуляцией и интонацией положительно сказывается также на чтении вслух и выполнении устных речевых упражнений. Особый рост мотивации к изучению языка наблюдается у студентов, когда они начинают употреблять интонационные конструкции в речи.

Овладение орфографией - одна из важнейших задач обучения письму. По словам Э.Ю. Сосенко, «орфография, как и графика, определяет приемы и способы буквенного обозначения звуков речи, но делает это с учетом конкретных слов в целом, их форм или морфем (корней, приставок, суффиксов, окончаний, соединительных гласных)» ${ }^{23}$.

С правилами русской орфографии наши студенты знакомятся по мере введения новых слов или грамматических форм. Обучение орфографии происходит непроизвольно в ходе обучения чтению и письму, поэтому более прочному и легкому усвоению правильного написания слов способствует комплексная подача языкового материала, когда на одном занятии студент слышит, читает и пишет новое слово.

Основном принципом русской орфографии является морфологический принцип. Это обозначает, что каждая морфема (суффикс, корень, приставка) пишется одинаково. Однако, в зависимости от фонетических условий, морфе-

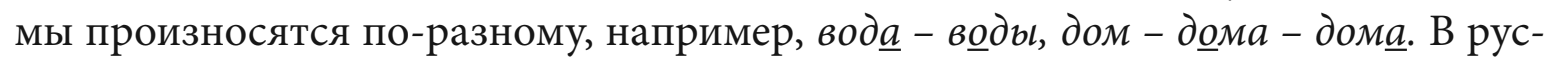
ском языке написание некоторых слов подчинено фонетическому принципу, т.е. эти слова пишутся согласно произношению, например, сыграть, безыдейнъци. Бывают случаи, когда слова пишутся согласно традиции, например, это касается буквы $b$ в окончании глаголов (читаещ $\underline{b}$, знаеш $\underline{b}$ ), а также букв $a$ и $о$ в одной и той же корневой морфеме (загоратьь - загар).

Овладение произношением йотированных гласных $e, \ddot{e}, ю, я$ в ударном слоге и безударных слогах в положении после согласных позволяет преодолеть некоторые орфографические ошибки, совершаемые нашими студентами. Например, слова: тётя, бюро под влиянием польского языка ciocia, biuro они пишут: тиотиа, биуро. Устранить эти ошибки помогает запись этих слов с применением знаков транскрипции. Знание артикуляции облегчает осознание и усвоение орфографических правил, касающихся обозначения на письме мягкости согласного, правописания гласных после шипящих и $\mathcal{u}_{\text {. }}$

Поскольку русская орфография опирается на морфологический принцип, то при обучении орфографии особое внимание должно уделяться работе над

22 Zob. D. Dziewanowska. Aspektowo-kompleksowe nauczanie akcentuacji na studiach rusycystycznych, Kraków: Wydawnictwo Naukowe Akademii Pedagogicznej, 2005.

23 Э. Ю. Сосенко. Обучение письменной речи..., с. 144-145. 
значимыми элементами слов. В данном случае полезно применять морфологоорфографический анализ, например, выделение корневых или приставочных морфем, сопоставление с родственными словами. Эта форма работы способствует запоминанию правильного написания слов.

В процессе формирования орфографических навыков используются разного рода диктанты: зрительные, зрительно-слуховые, слуховые, самодиктанты. При проведении диктантов следует стремиться к тому, чтобы студенты безошибочно записывали диктуемое, а также чтобы умели обосновать правильность или неправильность написанного. Поэтому студенты должны осознанно усваивать определенные орфографические правила. В работе по усвоению правила должен соблюдаться принцип постепенности в нарастании трудностей. Объяснения, касающиеся применения правила, должны предшествовать написанию диктанта. Целесообразно также приводить правила после написания диктанта. Такой анализ написанного обладает обучающими ценностями.

В процессе обучения орфографии полезно также выполнять и другие упражнения, такие как: списывание, усложненное дополнительными заданиями, например, подчеркиванием определенных букв, заполнением пропусков; группировка слов, например, слов, сходных по составу или тематически связанных слов. По нашему мнению, ценным упражнением является работа со словарем. Например, при изучении приставок пре- и при- студентам дается задание выписать из орфографического словаря двадцать слов с этими приставками, а затем объяснить их значение и правописание. С этими словами студенты составляют предложения. Хорошие результаты дает также письмо по памяти. Материалом для такого упражнения могут служить разнообразные тексты.

Работа над орфографией, конечно, должна продолжаться и после завершения алфавитного курса. Это связано с тем, что в рамках этого курса невозможно ознакомить студентов со всеми правилами русского правописания. Обучение орфографии должно осуществляться в тесной связи с обучением письменной речи $^{24}$.

Подытоживая, следует ещё раз подчеркнуть, что в ходе алфавитного курса должны параллельно закладываться основы русской графики, каллиграфии, фонетики и орфографии. В это время студенты знакомятся с буквами русского алфавита, с системой фонем русского языка, артикуляцией русских звуков, качественными особенностями русского ударения, ритмическими моделями одно- и многосложных слов, основными типами интонационных конструкций, а также изучают орфографический и лексико-грамматический материал. Параллельное обучение подсистемам языка становится наиболее результативным, когда оно строится на когнитивной основе. Очень важно, чтобы обучение технике письма полностью соответствовало принципу комплексности в обучении

24 См. Д. Дзевановская. Формирование умений в области письменной речи в процессе обучения нормам русской орфографии на младших курсах русистики. [В:] Новое в теории и практике описания и преподавания русского языка. Материалы научно-методической конференции, происходившей 6-7 мая 1999 года в Варшаве. Вып. VI. Ред. Н. Исаев, Й. Исаева, Т. Медзински. Варшава: Wydawnictwo Artico, 1999, с. 91-97. 
видам речевой деятельности, т.е. осуществлялось в тесной связи с обучением слушанию, говорению и чтению. Надо иметь в виду то, что приобретенные в ходе вводного алфавитного курса умения и навыки непрочны и быстро подвергаются разбалансированию; поэтому на всех последующих этапах обучения необходимо обращать пристальное внимание на соблюдение студентами норм русской каллиграфии, фонетики и орфографии.

\section{Литература}

Dziewanowska D. Aspektowo-kompleksowe nauczanie akcentuacji na studiach rusycystycznych. Kraków: Wydawnictwo Naukowe Akademii Pedagogicznej, 2005.

Dziewanowska D. Kształtowanie sprawności mownych w procesie nauczania języka rosyjskiego metoda reproduktywno-kreatywna w klasie Vi VI szkoły podstawowej. Seria Prace Monograficzne, nr 175, Kraków: Wydawnictwo Naukowe WSP, 1993.

Henzel J. Nauczanie języka rosyjskiego metoda reproduktywno-kreatywna Kraków: Wydawnictwo Naukowe WSP, 1978.

Балыхина Т.М. Методика преподавания русского языка как неродного (нового). Учебное пособие для преподавателей и студентов. Москва: Издательство Российского университета дружбы народов, 2007.

Дзевановская Д. Новые требования к обучению русскому образиовому произномению польских студентов-русистов, изучающих русский язык с нулевого уровня. «Studia Rossica Posnaniensia» 2013, № 38. Ред. Е. Калишан, s. 53-63.

Дзевановская Д. Формирование умений в области письменной речи в процессе обучения нормам русской орфографии на младших курсах русистики. [В:] Новое в теории и практике описания и преподавания русского языка. Материалы научно-методической конференции, происходившей 6-7 мая 1999 года в Варшаве. Вып. VI. Ред. Н. Исаев, Й. Исаева, Т. Медзински. Варшава: Wydawnictwo Artico, 1999, с. 91-97.

Капитонова Т.И., Московкин Л.В. Методика обучения русскому языку как иностранному на этапе подготовки. Санкт-Петербург: Златоуст, 2006.

Лебединский С. И., Гербик Л. Ф. Методика преподавания русского языка как иностранного. Учебное пособие. Минск, 2011. [Online:] <www.bsu.by/Cache/pdf/365803.pdf> (20.01.2016)

Рычкова М.А. Каллиграбия для взрослых, Учебное пособие. Улан-Удэ: ФГОУ ВПО Бурятская государственная сельскохозяйственная академия им. В.Р. Филиппова, 2009.

Сосенко Э.Ю. Обучение письменной речи. [В:] Методика. Заочный курс повышения квалификации филологов-русистов. Ред. А.А. Леонтьев. Москва: Русский язык, 1988, с. 142-151. 